\title{
Assessment of Environmental Fluctuations in Phytochemical Constituents of Some Xerophytes Inhabiting Wadi Sudr and their Antimicrobial Bioactivity
}

\author{
Samar Samir Mohamed ${ }^{(1) \#}$, Hemmat Khattab ${ }^{(2)}$ and Amal Morsy ${ }^{(2)}$ \\ (1) Microbiology Department, Faculty of Science, Ain Shams University, Cairo, Egypt; \\ ${ }^{(2)}$ Botany Department, Faculty of Science, Ain Shams University, Cairo, Egypt.
}

\begin{abstract}
RADITIONAL medicinal plants are an important economic source of raw materials for the drug industry. Nowadays, searching for new sources of drug raw materials is an important issue to meet the ever increasing demands. Therefore, quantitative and qualitative phytochemical screening of the dominated xerophytes inhabiting Wadi Sudr, South Sinai, including Retama raetam, Reaumaria hirtella, Tamarix nilotica and Zygophyllum dumosum, was performed. The accumulation levels of some natural bioactive products including phenols, flavonoids and saponins were determined during spring and summer. The investigated species exhibited significant increases in total free amino acids during spring, while they tend to accumulate total soluble sugars, sucrose and secondary metabolites including phenols, tannins and saponins during the dry summer season. Such increments in these metabolites were concomitant with the greatly reducing power capacity. Moreover, the antimicrobial activities of extracts from these shrubs were evaluated against four pathogenic microorganisms ( 2 bacterial species; Escherichia coli and Staphylococcus aureus and 2 fungal species; Candida albicans and Aspergillus fumigatus). Of the tested alternatives, methanolic extract was the most active fraction, while Tamarix nilotica was the most active plant species against the four tested microorganisms, especially Candida albicans. Furthermore, The MIC of the methanolic fraction of Tamarix nilotica and its effect on ergosterol and leakage of intracellular components of cells of Candida albicans showed that this shrub displays its fungicidal effects by targeting the ergosterol biosynthesis in Candida albicans and disrupting the membrane integrity. In conclusion, these shrubs are promising new sources for potent antioxidants and useful antimicrobial agents.
\end{abstract}

Keywords: Wadi Sudr, Xerophytes, Metabolites, Antioxidant, Antimicrobial activity.

\section{Introduction}

Wild medicinal plants emanate from their long use in folk medicines as well as their prophylactic properties, especially in developing countries. According to World Health Organization (WHO) more than $80 \%$ of the world's population relies on traditional medicine for their primary healthcare needs. Medicinal plants contain large varieties of chemical substances, which possess important therapeutic properties that could be utilized in the treatment of human diseases. The potential of higher plants as source of new drugs is still largely unexplored. Among the estimated 250,000-500,000 plant species, only a small percentage has been investigated phytochemically and the fraction submitted to biological or pharmacological screening is even smaller. Thus, any phytochemical investigation of a given plant will reveal only a very narrow spectrum of its constituents. Historically, pharmacological screening of compounds of natural or synthetic origin has been the source of numerous therapeutic agents. Random screening as a tool in discovering new biologically active molecules has been most productive in the area of antibiotics (Kroschwitz \& How e-Grant, 1992 and Mahesh \& Satish, 2008).

Plants generally produce several secondary metabolites like phenols, flavonoids, quinones, tannins, alkaloids, saponins, and sterols which are important sources of biocides and many other pharmaceutical drugs (Naili et al., 2010). Moreover, a large number of wild plants has been investigated for their antioxidant properties. Natural antioxidants either in the form of raw extracts or their chemical constituents are very

"Corresponding author email: samar_samer78@yahoo.com

Edited by: Prof. Dr. Wedad Kasim, Faculty of Science, Tanta University, Tanta, Egypt.

DOI: 10.21608/ejbo.2018.3690.1174

C2018 National Information and Documentation Center (NIDOC) 
effective in neutralizing reactive oxygen species (ROS) and thereby, preventing the destructive processes caused by oxidative stress (Zengin et al., 2011). Considerable evidence has been gathered and indicated the key roles of ROS and other oxidants in causing numerous disorders and diseases. Meanwhile, the human body has an inherent antioxidative mechanism and many of the biological functions such as the antimutagenic, anti-carcinogenic and anti-aging responses originate from this property (Gocer \& Gulcin, 2011 and Gulcin, 2012). Medicinal plants also represent a rich source of antimicrobial agents (Mutasa et al., 2015).

Wadi Sudr is one of the largest and most developed wadis in south west Sinai. W. Sudr is exposed to several environmental variables, which have impacted the ecosystem particularly the vegetation. Four xerophytes Retama raetam (True xerophyte), Reaumaria hirtella (Crynohalophyte), Tamarix nilotica (Crynohalophyte) and Zygophyllum dumosum (Succulent xerophyte) were chosen for exploiting the antioxidant level and bioactivity of secondary metabolites during spring and summer. The aim of this study was to evaluate in vitro antioxidant as well as the antimicrobial properties of different extracts of some wild plants collected from Wadi Sudr.

\section{Materials and Methods}

Location of the study area

Wadi Sudr is one of the most developed wadis of the southern section of the western coast of Sinai, delimited by latitudes $29^{\circ} 36^{\prime} 54^{\prime \prime}$ $29^{\circ} 51^{\prime} 54^{\prime \prime} \mathrm{N}$ and longitudes $32^{\circ} 41^{\prime} 30^{\prime \prime}-33^{\circ} 09^{\prime}$ 07" E. It is bounded by Gebel El Raha (c. 600m) in the north and Sinn Bishr (c. 618m) in the south. The main trunk of the wadi extends roughly in a NE-SW direction for about $55 \mathrm{~km}$ and flows into the Suez Gulf at Ras Sudr town (C. $55 \mathrm{~km}$ south of El-Shatt). The wadi originates in the hill.

\section{Plant analysis}

Plant collection

The aerial parts of Retama raetam, Reaumaria hirtella, Tamarix nilotica and Zygophyllum dumosum shrubs of similar age and size were collected from different sites of Wadi Sudr located in South Sinai during spring and summer. The plants were identified by botany department, Ain Shams University. The fresh and air-dried aerial parts of Retama raetam, Reaumaria hirtella, Tamarix nilotica and Zygophyllum dumosum were subjected to pigments and metabolic analysis, respectively as well as the antimicrobial activity.

\section{Analysis of primary metabolites}

Determination of total soluble carbohydrates: Total soluble carbohydrates were extracted following the method of Homme et al. (1992) and determined using anthrone reagent according to the method described by Fairbairn (1953).

Determination of sucrose: Sucrose content was estimated according to the method described by Hubbard \& Pharr (1992). The concentration of sucrose was determined from the standard curve of sucrose and calculated as $\mathrm{mg} / \mathrm{g}$ dry weight.

Determination of total free amino acids: Free amino-acids were determined photometrically with ninhydrin according to the procedure described by Muting \& Kaiser (1963). The concentration of amino acids was finally determined from the standard curve of glycine and calculated as $\mathrm{mg} / \mathrm{g}$ dry weight.

\section{Analysis of secondary metabolites}

Extraction of phytochemicals: After complete shade drying, the plant materials $(100 \mathrm{~g})$ were grinded with a mechanical grinder and the powder was kept in tightly closed containers. Plant material $(20 \mathrm{~g})$ was soaked for $6 \mathrm{~h}$ in $100 \mathrm{ml}$ of distilled water in tightly sealed vessels at room temperature. The methanolic, hexan and petroleum ether extracts were prepared by extracting the dry leaves powder $(20 \mathrm{~g})$ three times each with $100 \mathrm{ml}$ of solvent. All crude extracts were filtered through Whatman filter paper and kept at $4^{\circ} \mathrm{C}$ until tested.

Determination of total polyphenol content and tannins: The polyphenol and tannin contents were determined according to the methods described by Makkar et al. (1993). The total phenolic content was expressed as mg tannic acid equivalents/g sample.

Determination of total flavonoids content: To confirm the presence of flavonoids, the method of Woisky \& Salatino (1998) was used. The total flavonoid content was calculated as $\mu \mathrm{g} \mathrm{g}^{-1}$ dry weight from the standard curve of quercetin.

Determination of saponins: The presence of saponins was demonstrated by the methods of 
Makkar et al. (2007). The total Saponin content was calculated as $\mathrm{mg} \mathrm{g}^{-1}$ dry weight from the standard curve of diosgenin.

Determination of free radical scavenging activity: The free radical scavenging activity of the fractions was measured by 2, 2- diphenyl 1-1-picrylhydrazyl (DPPH) assay according to Bursal \& Gulcin (2011). The scavenging activity was estimated based on the percentage of DPPH radical scavenged as the following equation:

Scavenging effect $\%=$ (Control absorbance) $-($ Sample absorbance) $) \times 100$ Control absorbance

\section{Antimicrobial activity assay}

Microbial species

Two species of pathogenic bacteria; Escherichia coli, Staphylococcus aureus and two species of pathogenic fungi; Candida albicans and Aspergillus fumigatus were used as test organisms. All pathogenic organisms were obtained from Ain Shams University, Specialized Hospital. Bacterial strains were grown on nutrient agar slants for $24 \mathrm{~h}$ at $37^{\circ} \mathrm{C}$, Candida albicans and Aspergillus fumigatus were grown on potato dextrose agar at $28^{\circ} \mathrm{C}$ for $2-4$ days. For bacterial and yeast strains, the culture was gently swabbed, and the suspension was transferred to a sterile tube, then adjusting the concentration using the $0.5 \mathrm{McF}$ arland standard tubes. This will give a suspension of $10^{6} \mathrm{spores} / \mathrm{ml}$ (CLSI M27-A3, 2008a). For fungal strain, spore suspensions were counted with a hemocytometer to a concentration of 0.5-4 x104 spores/ml (CLSI M38-A2, 2008b).

\section{Preparation of plant extracts}

Extracts of the four tested xerophytes collected during summer season were prepared at a concentration of $100 \mathrm{mg} / \mathrm{ml}$ using different solvents viz. Methanol, ethyl acetate and water.

\section{Antibacterial and antifungal assessment of plant extracts \\ The surface of Muller Hinton (MH) agar} plates was streaked in 4 different directions (at 90-degree angles) to cover the entire surface and allowed to dry at $35^{\circ} \mathrm{C}$. The agar was allowed to set and harden and the required numbers of holes were cut using a sterile cork borer, Agar plugs were removed. Amphotericin and Chloramphenicol $(1 \mathrm{mg} / \mathrm{ml})$ were used as positive control for fungal and bacterial strains, respectively. About 200 $\mu$ l of different concentrations of plant solvent extracts were put into the wells and allowed to diffuse at room temperature for $1 \mathrm{~h}$. The plates were incubated at $37^{\circ} \mathrm{C}$ for $18-24 \mathrm{~h}$ for bacterial pathogens and $28^{\circ} \mathrm{C}$ for 2-4 days for fungal pathogens. The diameter of the inhibition zone (DIZ) was measured in $\mathrm{mm}$ and the activity index was also calculated. The experiment was repeated twice, where for each replicate. The diameters of the inhibitory zones were measured in three different fixed directions and the average values were recorded (Magaldi et al., 2004).

\section{Determination of minimum inhibitory concentration (MIC) \\ The minimum inhibitory concentration} (MIC) was determined according to the Clinical Laboratory Standards Institute M27-A3 microdilution method (CLS, 2002) using 96-wells microtiter plates. $100 \mu \mathrm{L}$ of two-fold diluted fractions and reference drugs in RPMI 1640 (Sigma Aldrich) were added in the wells of the microtiter plate followed by addition of $100 \mu \mathrm{L}$ of C. albicans inoculum standardized at $2.5 \times 10^{3} \mathrm{cells} /$ $\mathrm{ml}$. The plate was incubated at $30^{\circ} \mathrm{C}$ for $24 \mathrm{~h}$. The MIC was determined spectrophotometrically with a microplate reader at $595 \mathrm{~nm}$. MIC was defined as the lowest concentration that inhibited visible fungal growth.

\section{Determination of ergosterol content}

Ergosterol content in the plasma membrane was measured according to Tian et al. (2012). An amount of $100 \mathrm{ml}$ containing $10^{7} \mathrm{spores} / \mathrm{ml}$ (the spore population was counted using a hemocytometer) of C. albicans spore suspension was inoculated in a Potato Dextrose Broth (PDB) medium containing sub inhibitory concentrations of methanolic extract of Tamarix nilotica. Samples without any oil treatment were considered as controls. After incubation, cells were harvested and washed twice with distilled water. The net wet weight of the cell pellet was determined. Five milliliters of $25 \%$ alcoholic potassium hydroxide solution were added to each sample and vortex mixed for $2 \mathrm{~min}$, followed by incubation at $85^{\circ} \mathrm{C}$ for $4 \mathrm{~h}$. Sterols were extracted from each sample by adding a mixture of $2 \mathrm{ml}$ sterile distilled water and $5 \mathrm{ml}$-heptane. The mixture was then sufficiently mixed by vortex for $2 \mathrm{~min}$ allowing the layers to separate for $1 \mathrm{~h}$ at room temperature. The n-heptane layer was analyzed using scanned spectrophotometry between 230 and $300 \mathrm{~nm}$. The presence of ergosterol (at 282nm) and the late sterol intermediate 24(28) dehydroergosterol (at 230 and 282nm) in the n-heptane layer led to a characteristic curve. Ergosterol amount was 
calculated as a percentage of the wet weight of the cells and was based on the absorbance and wet weight of the initial pellet. The calculated formula of the ergosterol amount is as follows:

$\%$ total ergosterol $+\%$ 24(28) dehydroergosterol= (A282/290)/pellet weight

\% 24(28) dehydroergosterol= $(\mathrm{A} 230 / 518) /$ pellet weight

$\%$ ergosterol $=[(\%$ total ergosterol $+\% 24(28)$ dehydroergosterol) - (\% 24(28) dehydroergosterol)]

where 290 and 518 are the E values (in percentages per $\mathrm{cm}$ ) determined for crystalline total ergosterol and 24(28) dehydroergosterol, respectively and pellet weight is the net wet weight $(\mathrm{g})$.

\section{Effect on cell membrane integrity}

This assay was performed to determine the ability of the plant extracts to alter the fungal cell membrane integrity causing leakage of intercellular molecules (Cordeiro et al., 2014). Candida albicans was exposed to $\mathrm{MIC} / 2$ of the methanolic extract of Tamarix nilotica. Growth control (without extract) and blank solution (culture medium only) were also included in the test. One millimeter from the tube containing the fungal inoculum and methanolic extract of plant was transferred to sterile microcentrifuge tubes and centrifuged for $15 \mathrm{~min}$. $(13,400 \mathrm{x} \mathrm{g})$. Of the supernatant, $70 \mu \mathrm{l}$ were removed from each tube and diluted 1:10 with sterile distilled water and the absorbance of the content was measured spectrophotometrically at 260 and $280 \mathrm{~nm}$ for nucleic acid and proteins, respectively.

\section{Statistical analysis}

In plant analysis, three replicates were used. The results were statistically analyzed using the SPSS (Statistical Package for Social Scientists) software, version 17. Data was statistically analyzed using Duncan's multiple range test $(\mathrm{P}>0.05)$ between mean values for the results of spring and summer seasons as described by Snedecor \& Cochran (1980).

\section{Results and Discussion}

\section{Plant analysis}

The spatial and seasonal variations in the succulence, pigments levels and some metabolites were investigated in four dominant and codominant xerophytes including Zygophyllum dumosum (succulent xerophyte), Retama raetam (nonsucculent "true" xerophyte) and Tamarix nilotica and Reaumuria hirtella (crynohalophytes) inhabiting Wadi Sudr (South Sinai).

\section{Analysis of primary metabolites}

The physiological and biochemical processes are altered by stress such as water relation (Silva et al., 2015), gas exchange, photosynthesis (Pagter et al., 2005) and the metabolism of carbohydrates, protein, amino acids and other organic compounds (Šircelj et al., 2005).

\section{Total soluble sugars}

Soluble sugars might play a central role in photochemical apparatus protection and ROS scavenging in stressed plants. Total soluble sugars content increased significantly during summer in all the four-studied species (Table 1). Total soluble sugars are negatively related to the pigment content in the all investigated species. The increments in sugars under water scarcity resulted from the decrease of photosynthesis, which was associated with an increase in respiration rate and led to the reduction in carbohydrates concentration in plant and hence the breakdown of starch into free soluble sugars needed for osmoregulation (Rosa et al., 2009). Carbohydrates act as a nutrient and also works as signaling molecules, modulating the expression of large number of genes (Osuna et al., 2007) and they are also involved in the response to abiotic stresses. Drought generally reduces the biochemical capacity for carbon assimilation and utilization. The adaptation of plants to heat stress induced accumulation of metabolites that serve as compatible solutes in chloroplasts, which were related to enhance thermostability (Hasegawa \& Bressan, 2000). Similar results have been reached by Zhou et al. (2013) on Tamarix ramosissima.

\section{Sucrose}

Sucrose is the dominant form of carbohydrate transported to developing plant organs and is one of the stored sugars in higher plants (Khayat \& Zieslin, 1987). Sucrose also serves as an osmotic solute (Rekikia et al., 1998). The early increase in sucrose content may be an adaptive response to water deficiency, as it may induce a shift in the partitioning of carbon in favor of sucrose synthesis (Castrillo, 1992). It is of interest to notice that Tamarix nilotica showed the highest significant value of sucrose content among all the studied plants during summer, while it attained the lowest value 
during spring (Table 1). Higher sucrose levels in the leaves of water-stressed plants might contribute to improved drought tolerance by decreasing osmotic potential in leaves in response to prolonged periods of water stress (Fu et al., 2010). The data implies that increase in sucrose content might be a possible explanation to the increase in production of total flavonoids and phenolics. The result agreed with the finding of Guo et al. (2011), who proposed that the increase in production of plant secondary metabolites that were observed in their studies on broccoli was due to increased production of sucrose.

In plants, carbohydrates produced by photosynthesis play vital roles as sources of energy and carbon skeletons for organic compounds and storage components as well as antioxidants and secondary metabolites. Carbohydrates contributed in ROS production and scavenging in plants exposed to abiotic stresses (Keunen et al., 2013). Moreover, carbohydrates play potential key roles in plant immunity as an essential element for plant defenses against microbes and participate in the regulation of defense genes (Bolouri-Moghaddam \& Van Den Ende, 2013 and Trouvelot et al., 2014). So, carbohydrates could be helpful in controlling plant diseases in field conditions (Delaunois et al., 2014).

Total free amino acids

The total free amino acids accumulation in the studied species displayed remarkable changes according to seasons and location variations. There is a tendency in accumulation of free amino acids during spring (Table 2). The reduction in free amino acids accumulation during summer might be due the decline in soil moisture content which reduce the uptake and transport of nitrogen, thereby amino acid biosynthesis and utilization in protein synthesis which might participate in root growth and fruit development. The reduction in the total free amino acids during summer may be also, due to the increase of the ability of the studied species to divert photoassimilates and changes the partitioning of carbon allocated to growth and secondary metabolism including phenols, lignin (Lavinsky et al., 2015).

Analysis of secondary metabolites (phytochemicals)

It was suggested that when plants are stressed, a trade-off occurs between allocating carbon to biomass production or the formation of defensive secondary compounds (Herms \& Mattson, 1992). The synthesis of secondary metabolites including phenols, flavonoids, saponins, tannins and cardiac glycosides was stimulated under environmental stresses on the expense of some primary metabolites to contribute in the adaptive strategy and leading to tolerance of abiotic stresses. Meanwhile, most of the secondary metabolites have significant ecological functions, including protection against microbial or insect attack and significant economic and medicinal purposes.

TABLE 1. Seasonal fluctuations in total soluble sugar $\left(\mathrm{mg}^{-\mathrm{g}^{-1}} \mathrm{DW}\right)$ and sucrose $\left(\mathrm{mg}^{\mathrm{g}} \mathrm{g}^{-1} \mathrm{DW}\right)$ contents of the studied species inhabiting Wadi Sudr.

\begin{tabular}{lcccc}
\hline \multirow{2}{*}{ Plant species } & \multicolumn{2}{c}{ Total soluble sugar (mg.g ${ }^{-1}$ dry wt.) } & \multicolumn{2}{c}{ Sucrose (mg . g $^{-1}$ dry wt.) } \\
\cline { 2 - 5 } & Spring & Summer & Spring & Summer \\
\hline Retama raetam & $1.65 \pm 0.04^{\mathrm{a}}$ & $1.86 \pm 0.14^{\mathrm{b}}$ & $0.34 \pm 0.03^{\mathrm{b}}$ & $0.43 \pm 0.08^{\mathrm{a}}$ \\
Reaumuria hirtella & $0.92 \pm 0.07^{\mathrm{a}}$ & $1.46 \pm 0.12^{\mathrm{c}}$ & $0.18 \pm 0.01^{\mathrm{a}}$ & $0.21 \pm 0.04^{\mathrm{ab}}$ \\
Tamarix nilotica & $2.91 \pm 0.14^{\mathrm{b}}$ & $3.00 \pm 0.17^{\mathrm{b}}$ & $0.55 \pm 0.09^{\mathrm{b}}$ & $0.16 \pm 0.01^{\mathrm{a}}$ \\
Zygophyllum dumosum & $2.88 \pm 0.21^{\mathrm{a}}$ & $4.16 \pm 0.21^{\mathrm{c}}$ & $0.62 \pm 0.07^{\mathrm{b}}$ & $0.43 \pm 0.05^{\mathrm{d}}$ \\
\hline
\end{tabular}

TABLE 2. Seasonal fluctuations in total amino acid $\left(\mathrm{mg}^{-g^{-1}} \mathrm{DW}\right)$ contents of the studied species inhabiting Wadi Sudr.

\begin{tabular}{lcc}
\hline \multirow{2}{*}{ Plant species } & \multicolumn{2}{c}{ Total amino acid (mg.g-1 dry wt.) } \\
\cline { 2 - 3 } & Spring & Summer \\
\hline Retama raetam & $6.21 \pm 1.41^{\mathrm{ab}}$ & $4.30 \pm 1.75^{\mathrm{ab}}$ \\
Reaumuria hirtella & $2.21 \pm 0.04^{\mathrm{b}}$ & $1.00 \pm 0.15^{\mathrm{a}}$ \\
Tamarix nilotica & $0.90 \pm 0.09^{\mathrm{b}}$ & $1.02 \pm 0.14^{\mathrm{b}}$ \\
Zygophyllum dumosum & $3.94 \pm 0.18^{\mathrm{c}}$ & $2.82 \pm 0.28^{\mathrm{b}}$ \\
\hline
\end{tabular}




\section{Phenols}

All tested species showed an increase in phenolic content during summer, except Retama raetam which showed a reverse response. Tamarix nilotica showed the greatest value of phenols during summer. Phenol synthesis and accumulation is generally stimulated in response to biotic or abiotic stresses (Muthukumarasamy et al., 2000). The accumulation of phenolic compounds may be attributed to disrupted metabolism caused by high radiation levels in arid regions thereby, the imbalance between phenolic compound synthesis and its use in the cell wall synthesis (Kefeli \& Kalevitch, 2003). It was also postulated that plants that grow under unfavorable environmental conditions, contain relatively large amounts of phenolic compounds (Sezai et al., 2008 and Patel $\&$ Patel, 2014) which play a role in cell acclimation against stress (Lee et al., 2003). In addition, phenolic compounds exhibit antioxidant activity by buffering lipid free radicals or by preventing hydroperoxides into free radicals (Pokorny et al., 2001). Water stress can stimulate the accumulation of phenolic compounds in desert plants during summer by hydrolyzing the glycosides (Gehlot et al., 2011). Consequently, the phenolics are powerful antioxidants in plant tissues under stress (Silva et al., 2015 and Kljusurić et al., 2016). They are chemically heterogeneous compounds and include flavonoids, lignins and tannins. They play various roles as they can act as antiherbivore and antipathogens, lend mechanical support, attract pollinators, absorb high energy radiations and reduce the growth of nearby competing plants (Harborne \& Williams 2000 and Taiz \& Zeiger, 2002).

\section{Tannins}

The studied plant species showed an increase in the tannins content during summer except Retama raetam which showed no significant difference between the two seasons and the different locations (Table 3). The combined stress of drought, high temperature and excessive light as well as salinity characteristic for desert habitat increased the production of polyphenolic compounds such as tannins (Ramakrishna \& Ravishankar, 2011; Ibrahim, 2012 and Abdolzadeh et al., 2014). The occurrence of large amount of tannins can confer protection and acclimation against biotic and abiotic stresses. Tannins can neutralize reactive oxygen species (Bekerecioglu et al., 1998). They are generally antitoxins that can reduce the growth and survival of many herbivores and serve as defenses against microorganisms (War et al., 2012 and Redondo et al., 2014).

\section{Flavonoids}

Chaves et al. (1993) reported that the flavonoid content of plants is known to vary quantitatively and qualitatively depending on the growth stage, degree of senescence, season and geographical location. Flavonoids have been shown to be highly effective scavengers of most oxidizing molecules (Havsteen, 2002 and Tahara, 2007) and implicated to confer protection to plants grown under stresses (WinkelShirley, 2002 and Gould, 2004). Retama raetam and Reaumuria hirtella showed an increase in flavonoid content in spring, while Tamarix nilotica and Zygophyllum dumosum showed a reverse effect during summer. Similarly, the phenolic content of Tamarix nilotica recorded the highest mean value (2 folds) of total flavonoids content during summer (Table 3). The increments in the total flavonoids in the dry hot season particularly may be associated to the gradient of environmental conditions imposed by high temperature, relative humidity and solar radiation. Similar results have been obtained by Ahmed et al. (2014) and Patel \& Patel (2014) on Vernonia schimperi, Tecomella on undulate and Khodaie et al. (2012) on Pedicularis L., respectively.

\section{Saponins}

Saponins are glycosides accumulated in many plants. They display hemolytic, expectorative, antiinflammatory and immune- stimulating activity and antimicrobial properties particularly against fungi and additionally against bacteria and protozoa (Westendarp, 2005). The studied species showed an increase in saponin content during summer except for Retama raetam_(Table 3). The increments in saponins level in summer might be due to the differential synthesis and/or accumulation of saponins and their aglycones which depend on species or genotype, age and environmental conditions (Inderjit \& Foy, 1999 and Golawska et al., 2006). The accumulation of saponins could be related to its protective role against oxidative stress (Kim et al., 2012 and Szakiel et al., 2009). Our results were in line with De Costa et al. (2013) and Odjegba \& Alokolaro (2013) on Quillaja brasiliensis and Acalypha wilkesiana, respectively. Moreover, the combined influence of agro-climatic conditions was shown to affect the quantity of saponins (Szakiel et al., 2011 and Moses et al., 2014). In contrast, the reduction in saponins in $R$. raetam was also reported by Solı' z-Guerrero et al. (2002) in water stressed Chenopodium quinoa. 
TABLE 3. Seasonal fluctuations in total phenols, tannins, flavonoids and saponins contents (mg. $\left.\mathrm{g}^{-1} \mathrm{DW}\right)$ of the studied species inhabiting Wadi Sudr.

\begin{tabular}{|c|c|c|c|c|c|c|c|c|}
\hline \multirow[t]{2}{*}{ Plant species } & \multicolumn{2}{|c|}{$\begin{array}{l}\text { Total phenols } \\
\text { (mg.g-1 dry wt.) }\end{array}$} & \multicolumn{2}{|c|}{$\begin{array}{c}\text { Total tannins } \\
\text { ( } \mu \text { g.g }{ }^{-1} \text { dry wt.) }\end{array}$} & \multicolumn{2}{|c|}{$\begin{array}{l}\text { Total flavonoids } \\
\text { ( } \mu \mathrm{gg}^{-1} \text { dry wt.) }\end{array}$} & \multicolumn{2}{|c|}{$\begin{array}{l}\text { Total saponins } \\
\text { (mg.g }{ }^{-1} \text { dry wt.) }\end{array}$} \\
\hline & Spring & Summer & Spring & Summer & Spring & Summer & Spring & Summer \\
\hline Retama raetam & $2.68 \pm 0.23^{b}$ & $1.12 \pm 0.58^{\mathrm{b}}$ & $2.98 \pm 0.2^{\mathrm{a}}$ & $2.68 \pm 0.96^{\mathrm{a}}$ & $3.27 \pm 0.42^{\mathrm{a}}$ & $3.45 \pm 0.79^{\mathrm{a}}$ & $4.18 \pm 0.31^{\mathrm{a}}$ & $4.05 \pm 0.18^{a}$ \\
\hline $\begin{array}{l}\text { Reaumuria } \\
\text { hirtella }\end{array}$ & $2.28 \pm 0.12^{\mathrm{a}}$ & $2.53 \pm 0.14^{b}$ & $1.34 \pm 0.01^{\mathrm{a}}$ & $1.91 \pm 0.06^{\mathrm{b}}$ & $5.49 \pm 0.41^{\mathrm{c}}$ & $3.58 \pm 0.3^{\mathrm{a}}$ & $0.35 \pm 0.01^{\mathrm{c}}$ & $0.53 \pm 0.04$ \\
\hline $\begin{array}{l}\text { Tamarix } \\
\text { nilotica }\end{array}$ & $3.09 \pm 0.28^{b}$ & $3.68 \pm 0.24^{\mathrm{c}}$ & $1.43 \pm 0.29^{\mathrm{a}}$ & $2.80 \pm 0.17^{\mathrm{c}}$ & $5.63 \pm 0.20^{\mathrm{b}}$ & $10.48 \pm 0.6^{\mathrm{d}}$ & $0.68 \pm 0.11^{\mathrm{a}}$ & $2.41 \pm 0.17^{\circ}$ \\
\hline $\begin{array}{l}\text { Zygophyllum } \\
\text { dumosum }\end{array}$ & $1.58 \pm 0.2^{\mathrm{b}}$ & $1.90 \pm 0.16^{\mathrm{c}}$ & $1.47 \pm 0.08^{\mathrm{a}}$ & $2.44 \pm 0.19^{\mathrm{b}}$ & $2.49 \pm 0.44^{\mathrm{a}}$ & $5.46 \pm 0.12^{\mathrm{b}}$ & $1.87 \pm 0.14^{\mathrm{a}}$ & $2.84 \pm 0.04^{c}$ \\
\hline
\end{tabular}

Total antioxidant capacity

All studied plant extracts exhibited antioxidant activity. The greatest reducing power was measured during hot summer season (Table 4). Similar results have been reached by Ahmed et al. (2014) who observed increments in the total antioxidant capacity of Melilotus indicus methanolic extract collected during summer. This was concomitant with the increments in the magnitudes of antioxidants such as phenols, flavonoids and tannins which may suggest the involvement of antioxidants in the main strategy of adaptation of the studied species to arid environment. Moreover, phenolic acids and flavonoids seem to be the major contributors for the increments in the total antioxidant activity and thereby the highly effective scavengers of most oxidizing molecules (Nunes et al., 2012 and López-Marín et al., 2013). The results of the present investigation showed that the increase in sucrose content was concomitant with production of secondary metabolites. Such results are in accordance with these reported by Briskin \& Gawienowski (2001) who observed that sucrose might have influence on the up regulation of secondary metabolites.

Antimicrobial activity

Antimicrobial activity of aqueous, methanolic and ethyl acetate extracts of the four plants (Retama raetam, Reaumuria hirtella, Tamarix nilotica and Zygophyllum dumosum) showed variable results against the four microbial strains (Staphylococcus aureus, Echerichia coli, Candida albicans and Aspergillus fumigatus). The methanolic extract of Tamarix nilotica showed the highest antimicrobial activity against all tested microorganisms followed by the aqueous extract of the same plant. This might be related to the greater accumulation of secondary metabolites especially phenols and flavonoids accumulated in $T$. niltoica. It could also be related to the fact that $T$. nilotica being a crynohalophyte which accumulates high amount of minerals in its tissue which had an inhibitory effect on the microorganisms. On the other hand, the extracts (aqueous, methanolic and ethyle acetae) of Retama raetam, Reaumuria hirtella lack the antimicrobial activity and Zygophyllum dumosum showed very weak activity (Table 5). Alghazeer et al. (2012) also mentioned that the antibacterial potential was increased notably using the methanol plant extracts than the activity of water extracts against both $\mathrm{G}+\mathrm{ve}$ and $\mathrm{G}$-ve bacteria. Candida albicans was the most susceptible strain to the methanolic extract of Tamarix nilotica followed by Aspergillus fumigatus, Staphylococcus aureus and finally Echerichia coli (Table 5 and Fig. 1).

TABLE 4. Percentage of DPPH free radical scavenging activity for all studied species.

\begin{tabular}{lcc}
\hline \multirow{2}{*}{ Plant species } & \% Free radical scavenging activity \\
\hline Retama raetam & Spring & Summer \\
\cline { 2 - 3 } Reaumuria hirtella & $28.56 \pm 1.36^{\mathrm{a}}$ & $85.65 \pm 0.83^{\mathrm{c}}$ \\
Tamarix nilotica & $18.80 \pm 0.50^{\mathrm{a}}$ & $32.13 \pm 1.66^{\mathrm{b}}$ \\
Zygophyllum dumosum & $14.53 \pm 1.51^{\mathrm{a}}$ & $42.61 \pm 1.28^{\mathrm{b}}$ \\
\hline
\end{tabular}


TABLE 5. In vitro antimicrobial activity of extracts from the four studied plant species by well diffusion method.

\begin{tabular}{|c|c|c|c|c|c|c|c|c|c|c|c|c|c|c|}
\hline \multirow{3}{*}{ Microbial species } & \multicolumn{14}{|c|}{ Inhibition zone diameter (mm) } \\
\hline & \multicolumn{3}{|c|}{ Reaumuria hirtella } & \multicolumn{3}{|c|}{ Retama raetam } & \multicolumn{3}{|c|}{ Tamarix nilotica } & \multicolumn{3}{|c|}{$\begin{array}{l}\text { Zygophyllum } \\
\text { dumosum }\end{array}$} & \multirow{2}{*}{$\underset{\text { B }}{\operatorname{Amp}}$} & \multirow[t]{2}{*}{$\mathrm{Ch}$} \\
\hline & Aq & Me & Et & Aq & Me & Et & $\mathbf{A q}$ & Me & Et & $\mathbf{A q}$ & Me & Et & & \\
\hline Staphylococcus aureus & ND & ND & ND & ND & ND & ND & 12 & 18 & 12 & 7 & 10 & 8 & NA & 29 \\
\hline Escherichia coli & ND & ND & ND & ND & ND & ND & 14 & 17 & 12 & 9 & 12 & 6 & NA & 20 \\
\hline Candida albicans & ND & ND & ND & ND & ND & ND & 14 & 22 & 10 & 10 & 12 & 8 & 24 & NA \\
\hline Aspergillus fumigatus & ND & ND & ND & ND & ND & ND & 12 & 20 & 10 & 8 & 10 & 7 & 25 & NA \\
\hline
\end{tabular}

Aq, Aqueous; Me, Methanolic; Et, Ethyle acteate; Amp.B, Amphotericin B; Ch, Chloramphenicol; NA, not applicable; ND, not detected.

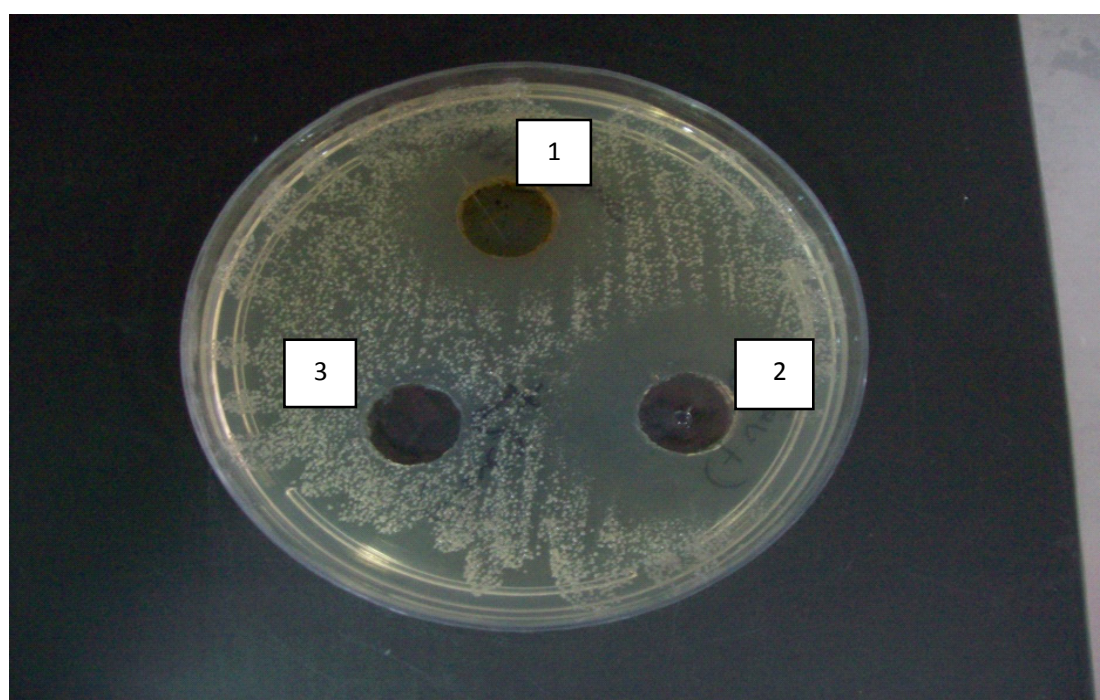

Fig. 1. In vitro anti-candida activity of methanolic extract of Tamarix nilotica.

Determination of the minimum inhibitory concentration (MIC)

The extent of inhibition on the fungal growth depends on the concentration used. The MIC of the most active plant extract (methanolic extract of Tamarix nilotica) was determined against most sensitive pathogenic microorganisms (Candida albicans). Results showed that the methanolic extract of Tamarix nilotica effectively inhibited the growth of Candida albicans at a low concentration $(\mathrm{MIC}=0.56 \mathrm{mg} / \mathrm{ml})$ when compared to amphotericin $\mathrm{B}$ ( $\mathrm{MIC}=0.70 \mathrm{mg} / \mathrm{ml})$ used as control. This result is similar to that reported by Omoruyi et al. (2014) who found that the essential oil of Mesembryanthemum edule extract tested against the pathogenic fungi, inhibited Candida albican, Candida krusei, Candida rugosa, Candida glabrata and Cryptococcus neoformans with MICs range of $0.02-0.31 \mathrm{mg} / \mathrm{ml}$. The activity of the essential oil was found comparable with nystatin and amphotericin B used as control.

\section{Determination of ergosterol content}

Ergosterol is specific to fungi and is the major sterol component of the fungal cell membrane. It is also responsible for maintaining cell function and integrity (Rodriguez et al., 1985). The effect of the most active plant extract (methanolic extract of Tamarix nilotica) on ergosterol content of the plasma membrane of the most sensitive pathogenic microorganisms (Candida albicans) was determined. Results revealed that Tamarix nilotica can induce a considerable impairment of the ergosterol biosynthesis ( $55 \%$ compared to control). This was consistent with some previous studies that have exhibited that natural and synthetic drugs can cause a considerable reduction in the quantity of ergosterol (Arthington-Skaggs et al., 2000; Pinto 
et al., 2006 and Pinto et al., 2009). These results indicate that the plasma membrane is an important antifungal target of plant extracts.

\section{Effect on plasma membrane integrity}

Leakage of intercellular molecules of fungal cells is an indicator of effect of the extract on permeability of cell membrane. The effect of the most active plant extract (methanolic extract of Tamarix nilotica) on the integrity of cell membrane of the most sensitive pathogenic microorganisms (Candida albicans) was determined. The results showed that plant extract at a concentration of $\mathrm{MIC} / 2$ caused the leakage of nucleic acid (0.05) and protein (0.07) with a significant increase in absorbance higher than those obtained by control $(0.01)$ at (260 and $280 \mathrm{~nm}$, respectively). These results were similar to those of Brilhante et al. (2016) who reported that tyrosol caused leakage of protein and nucleic acid, emphasizing the effect of tyrosol on both cellular and nuclear membrane.

\section{Conclusion}

Antioxidative and antimicrobial properties of wild plants are proven to be of great interest in both health and industry. In this respect, the present study was designed to evaluate the in vitro antioxidant properties and antimicrobial activity of the four investigated plant extracts against various microorganisms. The results presented here give insight about the seasonal changes of the antioxidant and antimicrobial properties of those plants that have traditional uses in Egypt. Tamarix nilotica might be useful as an excellent antioxidant, antibacterial and antifungal agent. Additional studies are required on the mode of action of the active ingredients on pathogenic microorganisms.

\section{References}

Abdolzadeh, A., Faghani, E. and Asghari, F. (2014) Assessment of physiological and phytochemical responses of Althaea rosea L. to salinity stress. $A d v$. Environ. Biol. 8(21), 1263-1267.

Ahmed, S., Al-Rehaily, A.J. and Yousaf, M. (2014) Preliminary phytochemical screening of Vernonia schimperi. Int. J. Med. Chem. Anal. 4, 226-230.

Alghazeer, R., El-Saltani, H., Saleh, N., Al-Najjar, A. and Hebail, F. (2012) Antioxidant and antimicrobial properties of five medicinal Libyan plants extracts. Natural Science, 4(5), 324-335.
Arthington-Skaggs, B.A., Warnock, D.W. and Morrison, C.J. (2000) Quantitation of Candida albicans ergosterol content improves the correlation between in vitro antifungal susceptibility test results and in vivo outcome after fluconazole treatment in a murine model of invasive candidiasis. Antimicrob Agents Chemother, 44, 2081-2085.

Bekerecioglu, M., Tercan, M. and Ozyazgan, I. (1998) The effect of Gingko Biloba extract (Egb 761) as a free radical scavenger on the survival of skin flaps in rats. Scand. J. Plastic Reconstruction Hand Surgery, 32, 135-139.

Bolouri-Moghaddam, M.R. and Van Den Ende, W. (2013) Sweet immunity in the plant circadian regulatory network. J. Exp. Bot. 64, 1439-1449.

Brilhante, R.S.N., Caetano, E.P., Lima, R.A.C., Marques, F.J.F., Castelo-Branco, D.S.C.M., Melo, C.V.S., Guedesa, G.M., Oliveiraa, J.S., Camargoc, Z.P., Moreiraa, J.L.B., Monteirod, A.J., Bandeirae, T.J.P.G., Cordeiroa, R.A., Rochaa, M.G. and Sidrima, J.J.C. (2016) Terpinen-4-ol, tyrosol, and -lapachone as potential antifungals against dimorphic fungi. Brazilian Journal of Microbiology, 47, 917-924.

Briskin, D.P. and Gawienowski, M.C. (2001) Differential effects of light and nitrogen on production of hypericins and leaf glands in Hypericum perforatum. Plant Physiol. 39, 1075-1081.

Bursal, E. and Gülçin, I. (2011) Polyphenol contents and in vitro antioxidant activities of lyophilised aqueous extract of kiwifruit (Actinidia deliciosa). Food Research International, 44(5), 1482-1489.

Castrillo, M. (1992) Sucrose metabolism in bean plants under water deficit. Journal of Experimental Botany, 43(12), 1557-1561.

Chaves, N., Escuduro, J.C. and Gutierrez-Merino, C. (1993) Seasonal variation of exudate of Cistus ladanifer. J. Chem. Ecol. 19(11), 2577-2591.

Clinical Laboratory Standards (2002) "Reference Method for Broth Dilution Antifungal Susceptibility Testing of Yeasts", Approved standard. NCCLS document M27-A2. National Committee for Clinical Laboratory Standards, Wayne, PA.

Clinical Laboratory Standard Institute (2008a) "Reference Method for Broth Dilution Antifungal Susceptibility Testing of Yeasts", Approved standard, 
$3^{\text {rd }}$ ed., M27- A3, Wayne, PA: Clinical Laboratory Standard Institute.

Clinical Laboratory Standard Institute (2008b) "Reference Method for Broth Dilution Antifungal Susceptibility Testing of Filamentous Fungi", approved standard CLSI document M38-A2. Clinical Laboratory Standard Institute, Wayne, PA.

Cordeiro, R.A., Marques, F.J.F. and Cordeiro, R.A. (2014) Synthesis and antifungal activity in vitro of isoniazid derivatives against Histoplasma capsulatum var. capsulatum. Antimicrob Agents Chemother. 58, 2504-2511.

De Costa, F., Yendo, A.C. and Fleck, J.D. (2013) Accumulation of a bioactive triterpene saponin fraction of Quillaja brasiliensis leaves is associated with abiotic and biotic stresses. Plant Physiology Biochemistry, 66, 56-62.

Delaunois, B., Farace, G., Jeandet, P., Clément, C., Baillieul, F. and Dorey, S. (2014) Elicitors as alternative strategy to pesticides in grapevine? Current knowledge on their mode of action from controlled conditions to vineyard. Environ. Sci. Pollut. Res. Int. 21, 4837-4846.

Fairbairn, N.J. (1953) A modiefied anthrone reagent Chem. Ind. 31, 86 .

Fu, J.M., Huang, B.R. and Fry, J. (2010) Osmotic potential, sucrose level and activity of sucrose metabolic enzymes in tall fescue in response to deficit irrigation. J. Amer. Soc. Hort. Sci. 135, 506-510.

Gehlot, M., Kasera, P.K. and Hussian, S. (2011) Secondary metabolites produced during different seasons in some arid medicinal plants. Journal of Medicinal and Aromatic Plant Sciences, 33, 404406.

Gocer, H. and Gulcin, I. (2011) Caffeic acid phenethyl ester (CAPE): Correlation of structure and antioxidant properties. Int. J. Food Sci. Nutr. 62, 821-825.

Golawska, S., Leszczynski, B. and Oleszek, W. (2006) Effect of low and high-saponin lines of alfalfa on pea aphid. J. Insect. Physiol. 52, 737-743.

Gould, K.S. (2004) Nature's Swiss army knife: The diverse protective role of anthocyanins in leaves.
Journal of Biomedicine and Biotechnology, 5, 314320.

Gulcin, I. (2012)Antioxidant activity of food constituents: An overview. Arch Toxicol. 86(3), 345-391.

Guo, R., Yuan, G. and Wang, Q. (2011) Effect of sucrose and mannitol on the accumulation of healthpromoting compounds and the activity of metabolic enzymes in broccoli sprouts. Scientia Horticulturae, 128(3), 159-165.

Harborne, J.B. and Williams, C.A. (2000) Advances in flavonoid research since 1992. Phytochem. 55, 481504.

Hasegawa, P.M. and Bressan, R.A. (2000) Plant cellular and molecular responses to high salinity. Annual Review of Plant Physiology and Plant Molecular Biology, 51, 463-499.

Havsteen, B.H. (2002) The biochemistry and medical significance of the flavonoids. Pharmacol. Therap. 96, 67-202

Herms, D.A. and Mattson, W.J. (1992) The dilemma of plants: To grow or defend. Quarterly Review of Biology, 67, 283-335.

Homme, P.M., Gonalez, B. and Billard, J. (1992) Carbohydrate content, fructan and sucrose enzyme activities in roots, stubble and leaves of rye grass (Lolium perenne L.) as affected by source/sink modification after cutting. J. Plant Pysiol. 140, 282291.

Hubbard, N.L. and Pharr, D.M. (1992) Developmental changes in carbohydrate concentration and activities of sucrose metabolizing enzymes in fruit of two Capsicum annuum L. genotypes. Plant Sci. 86, 3339.

Ibrahim, M.M. (2012) "Instinctive Plant Tolerance Towards Abiotic Stresses in Arid Regions, Artificial Photosynthesis", Mohammad Najafpour (Ed.), ISBN: 978-953-307-966-0, InTech, Available from website http://www.intechopen.com/books/artificialphotosynthesis/instinctive-plant-tolerance-towardsabiotic-stressesin-arid-regions.

Inderjit, N.F. and Foy, C.L. (1999) Nature of the interference mechanism of mugwort (Artemisia vulgaris). Weed Technology, 13, 176-182. 
Kefeli, V. and Kalevitch, M. (2003) "Natural Growth Inhibitors and Phytohormones in Plants and Environment". Borsari, B. (Ed.). Kluwer Academic Publishers, Dordrecht, The Netherlands.

Keunen, E., Peshev, D., Vangronsveld, J., Van den Ende, W. and Cuypers, A. (2013) Plant sugars are crucial players in the oxidative challenge during abiotic stress: Extending the traditional concept. Plant Cell Env. 36, 1242-1255.

Khayat, E. and Zieslin, Z. (1987) Effect of night temperature on the activity of sucrose phosphate synthase, acid invertase and sucrose synthase in source and sink tissues of Rosa hybrida cv Golden Times. Plant Physiol. 84, 447-449.

Khodaie, L., Bamdad, S., Delazar, A. and Nazemiyeh, H. (2012) Antioxidant, total phenol and flavonoid contents of two Pedicularis L. species from Eastern Azerbaijan, Iran. BioImpacts: BI, 2(1), 43-57.

Kim, Y.A., Kong, C.S., Lee, J.I., Kim, H., Park, H.Y., Lee, H.S., Lee, C. and Seo, Y, (2012) Evaluation of novel antioxidant triterpenoid saponins from the halophyte Salicornia herbacea. Bioorg. Med. Chem. Lett. 22(13), 4318-4322.

Kljusurić, J.G., Mihalev, K., Bečić, I,. Polović, I,. Georgieva, M., Djaković, S. and Kurtanjek, Ž. (2016) Near-infrared spectroscopic analysis of total phenolic content and antioxidant activity of berry fruits. Food Technology and Biotechnology, 54(2), 236-242.

Kroschwitz, J.I. and How e-Grant, M. (1992) A review of: "Kirk-Othmer Encyclopedia of Chemical Technology", Kroschwitz, J.I. (Executive Ed.) and Howe-Grant, M. (Ed.), pp.1991-1998. 27 Volumes. John Wiley \& Sons Inc., New York, NY.

Lavinsky, A.O., Magalhaes, P.C., Avila, R.G., Diniz, M.M. and de Souza, T.C. (2015) Partitioning between primary and secondary metabolism of carbon allocated to roots in four maize genotypes under water deficit and its effects on productivity. Crop J. 3(5), 379-386.

Lee, S.E., Hwang, H.J., Ha, J.S., Jeong, H.S. and Kim, J.H. (2003) Screening of medicinal plant extracts for antioxidant activity. Life Sci. 73, 167-179.

López-Marín, J., González, A., Pérez-Alfocea, F., EgeaGilabert, C. and Fernández, J.A. (2013) Grafting is an efficient alternative to shading screens to alleviate thermal stress in greenhouse grown sweet pepper. Sci. Hortic. 149, 39-46.

Magaldi, S., Mata-Essayag, S., Hartung de Capriles, C., Perez, C., Colella, M.T., Carolina Olaizola and Yudith Ontiveros (2004) Well diffusion for antifungal susceptibility testing. Int. Journal of Infectious Diseases, 8, 39-45.

Mahesh, B. and Satish, S. (2008) Antimicrobial activity of some important medicinal plant extract against plant and human pathogens. World J. Agr. Sci. 4(s), 839-843.

Makkar, H.P., Blümmel, M., Borowy, N.K. and Becker, K. (1993) Gravimetric determination of tannins and their correlations with chemical and protein precipitation methods. Journal of the Science of Food and Agriculture, 61(2), 161-165.

Makkar, H.P.S., Francis, G. and Becker, K. (2007) Bioactivity of phytochemicals in some lesser-known plants and their effects and potential applications in livestock and aquaculture production systems. Animal, 1(9), 1371-1391.

Moses, T., Papadopoulou, K.K. and Osbourn, A. (2014) Metabolic and functional diversity of saponins, biosynthetic intermediates and semi-synthetic derivatives. Critical Reviews in Biochemistry and Molecular Biology, 49(6), 439-462.

Mutasa, T., Mangoyi, R. and Mukanganyama, S. (2015) The effects of Combretum zeyheri leaf extract on ergosterol synthesis in Candida albicans. Journal of Herbs, Spices \& Medicinal Plants, 21(2), 211-217.

Muthukumarasamy, M.S.D. and Gupta, Pannerselvam R. (2000) Enhancement of peroxidase, polyphenol oxidase and superoxide dismutase activities by triadimefon in $\mathrm{NaCl}$ stressed Raphanus sativus L. Biol. Plant. 43, 317-320.

Muting, R.D. and Kaiser, H.Z. (1963) Spectrophotometric method of determining of amino- $\mathrm{N}$ in biological materials by means of the ninhydrin reaction. Seyler's Zschr. Physiol. Chem. 332, 276.

Naili, M., Alghazeer, R., Saleh, N. and Al-Najjar, A. (2010) Evaluation of antibacterial and antioxidant activities of Artemisis campestris and Ziziphus lotus. Arab J. Chem. 3, 73-134. 
Nunes, X.P., Silva, F.S., Almeida, J.R.G.S., Lima, J.T., Ribeiro, L.A.A., Quintans-Junior, L.J. and Barbosa, Filho J.M. (2012) "Biological Oxidations and their Role in Nutrition and Health", Venketeshwer, R. (Ed.), pp 1-21. InTech, Publisher.

Odjegba, V.J. and Alokolaro, A.A. (2013) Simulated drought and salinity modulates the production of phytochemicals in Acalypha wilkesiana. Journal of Plant Studies, 2(2), 105-112.

Omoruyi, B.E., Afolayan, A.J. and Bradley, G. (2014) The inhibitory effect of Mesembryanthemum edule (L.) bolus essential oil on some pathogenic fungal isolates. BMC Complementary and Alternative Medicine, 14, 168.

Osuna, D., Usadel, B., Morcuende, R., Gibon, Y., Bläsing, O.E. and Höhne, M. (2007) Temporal responses of transcripts, enzyme activities and metabolites after adding sucrose to carbon-deprived Arabidopsis seedlings. Plant J. 49, 463-491.

Pagter, M., Bragato, C. and Brix, H. (2005) Tolerance and physiological responses of Phragmites australis to water deficit. Aquatic Botany, 81(2005), 285-299.

Patel, A.K. and Patel, I.C. (2014) Seasonal effects on some phytochemicals accumulation of tecomella undulate (SM.) seem. Advance Research in Pharmaceuticals and Biologicals, 4(1), 639-643.

Pinto, E., Pina-Vaz, C., Salgueiro, L., Goncalves, M.J. and Costa-de-Oliveira, S. (2006) Antifungal activity of the essential oil of Thymus pulegioides on Candida, Aspergillus and dermatophyte species. $J$ Med Microbiol. 55, 1367-1373.

Pinto, E., Vale-Silva, L., Cavaleiro, C. and Salgueiro, L. (2009) Antifungal activity of the clove essential oil from Syzygium aromaticum on Candida, Aspergillus and dermatophyte species. J. Med. Microbiol. 58, 1454-1462.

Pokorny, J., Yanishlieva, N. and Gordon, M. (2001) Antioxidants in food: Practical applications. Cambridge Woodhead Publishing Limited, 72(5), 145-171.

Ramakrishna, A. and Ravishankar, G.A. (2011) Influence of abiotic stress signals on secondary metabolites in plants. Plant Signaling \& Behavior, 6(11), 17201731.
Redondo, L.M., Chacana, P.A., Dominguez, J.E. and Fernandez Miyakawa, M.E. (2014) Perspectives in the use of tannins as alternative to antimicrobial growth promoter factors in poultry. Frontiers in Microbiology, 5, 118.

Rekikia, D., Nachit, M.M., Araus, I.L. and Monneveux, P. (1998) Effects of water deficit on photosynthetic rate and osmotic adjustment in tetraploid wheats. Photosynthetica, 35, 129-138.

Rodriguez, R.J., Low, C., Bottema, C.D. and Parks, L.W. (1985) Multiple functions for sterols in Saccharomyces cerevisiae. Biochim. Biophys. Acta, 837, 336-343.

Rosa, M., Prado, C., Podazza, G., Interdonato, R., Gonzalez, J.A. and Hilal, M. (2009) Soluble sugarsmetabolism, sensing and abiotic stress: A complex network in the life of plants. Plant Signal. Behav. 4, 388-393.

Sezai, E., Emine, O., Ozlem, O., Memnune, S. and Gungor, N. (2008) Seasonal variation of total phenolic, antioxidant activity, plant nutritional elements and fatty acids in tea leaves (Camellia sinensis var. sinensis clone derepazari 7) grown in turkey. Phamaceutical Biology, 46(10-11), 683-687.

Silva, B.J.C., Seca, A.M.L., Barreto, M.C. and Pinto, D.C.G.A. (2015) Recent breakthroughs in the antioxidant and anti-inflammatory effects of Morella and Myrica species. International Journal of Molecular Sciences, 16(8), 17160-17180.

Šircelj, H.M., Tausz, D. and Grill, Batiè F. (2005) Biochemical responses in leaves of two apple tree cultivars subjected to progressing drought. J. Plant Physiol. 162, 1308-1318.

Snedecor, G.W. and Cochran, W.G. (1980) "Statistical Methods". $7^{\text {th }}$ ed. Iowa State University Press, Ames, Iowa, USA.

Sol1'z-Guerrero, J.B., de Rodriguez, D.J., Rodr1'guezGarci'a, R., Angulo-Sa'nchez, J.L. and Me'ndezPadilla, G. (2002) Quinoa saponins: Concentration and composition analysis. In: "Trends in New Crops and New Uses", pp 110-114. Janick, J., Whipkey, A. (Ed.). ASHS Press, Alexandria.

Szakiel, A., Paczkowski, C. and Henry, M. (2009) Seasonal changes of triterpene acids and lignane content in Vaccinium myrtillus L. plant and its habitat. 
International Conference on saponins: New trends in saponins. Nancy (France), Abstracts p. 59.

Szakiel, A., Pączkowski, C. and Henry, M. (2011) Influence of environmental abiotic factors on the content of saponins in plants. Phytochemistry Reviews, 10, 471-491.

Tahara, S. (2007) A journey of twenty-five years through the ecological biochemistry of flavonoids. Bioscience, Biotechnology and Biochemistry, 71,1387-1404.

Taiz, L. and Zeiger, E. (2002) "Plant Physiology", $3^{\text {rd }}$ ed. Massachusetts: Sinauer Associates Inc Publishers.

Tian, J., Huang, B., Luo, X.L., Zeng, H. and Ban, X.Q. (2012) The control of Aspergillus flavus with Cinnamomum jensenianum Hand.-Mazz essential oil and its potential use as a food preservative. Food Chem. 130, 520-527.

Trouvelot, S., Héloir, M.C., Poinssot, B., Gauthier, A., Paris, F., Guillier, C. and Adrian, M. (2014) Carbohydrates in plant immunity and plant protection: Roles and potential application as foliar sprays. Frontiers in Plant Science, 5, 592.

War, A.R., Paulraj, M.G., Ahmad, T., Buhroo, A.A. Hussain, B., Ignacimuthu, S. and Sharma, H.C. (2012) Mechanisms of plant defense against insect herbivores. Plant Signaling \& Behavior, 7(10), 13061320.

Westendarp, H. (2005) Saponins in nutrition of swine, poultry and ruminants. Dtsch Tierarztl Wochenschr, 112(2), 65-70.

Winkel-Shirley, B. (2002) Biosynthesis of flavonoids and effect of stress. Current Opinion in Plant Biology, 5, 218-223.

Woisky, R.G. and Salatino, A. (1998) Analysis of propolis: Some parameters and procedures for chemical quality control. Journal of Apicultural Research, 37(2), 99-105.

Zengin, G., Aktumsek, A., Guler, G.O., Selim Cakmak, Y. and Yildiztugay, E. (2011) Antioxidant properties of methanolic extract and fatty acid composition of Centaurea urvillei DC. subsp. hayekiana Wagenitz. Rec. Nat. Prod. 5(2), 123-132.

Zhou, H.H., Chen, Y.N. and Li, W.H. (2013) Xylem hydraulic conductivity and embolism in riparian plants and their responses to drought stress in desert of Northwest China. Ecohydrology, 6(6), 984-993.

(Received 29/ 4/2018; accepted 25/6/2018)

$$
\begin{aligned}
& \text { تقيم التذبذبات البيئية في المكونات الكيميائية النباتية لبعض النباتات الجفافية التي تقطن }
\end{aligned}
$$

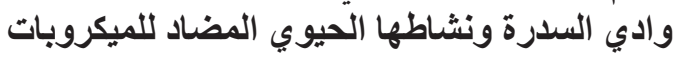

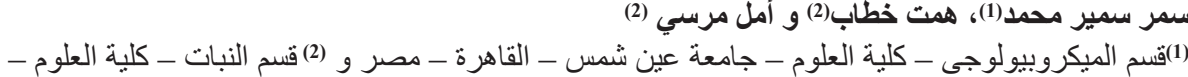

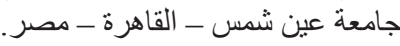

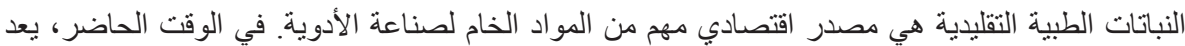

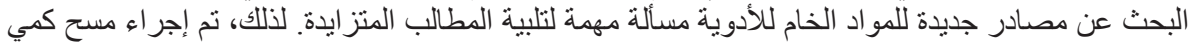

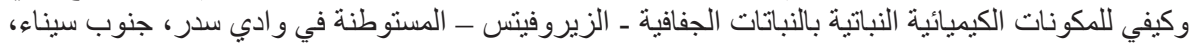

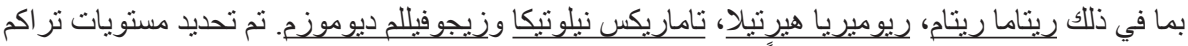

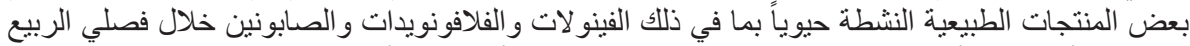

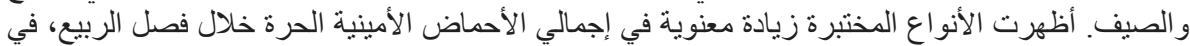

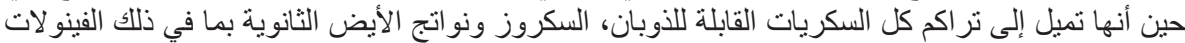

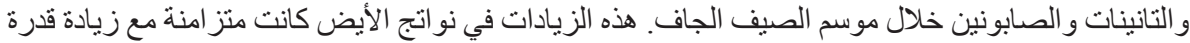

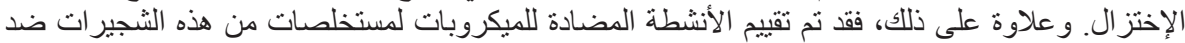

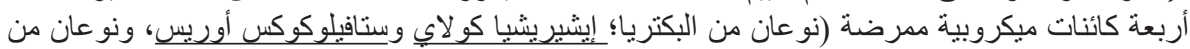

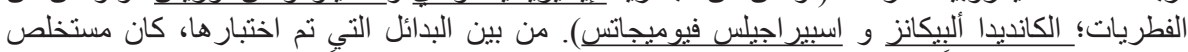

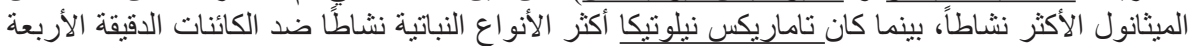

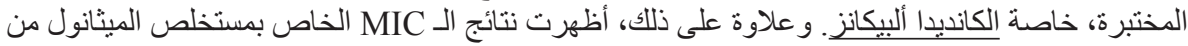

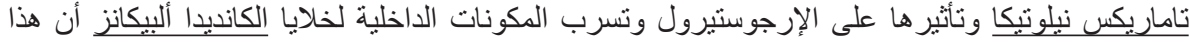

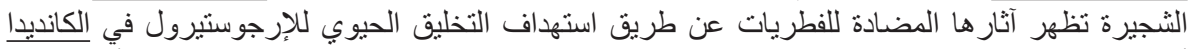

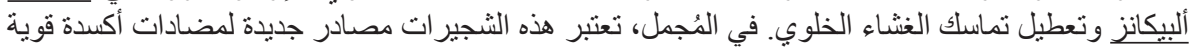

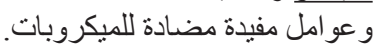

